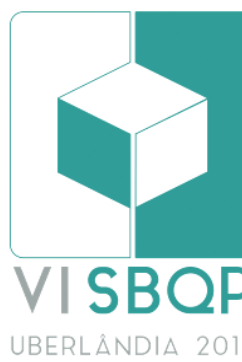

\title{
ANÁLISE DO PROGRAMA MINHA CASA MINHA VIDA NOS BAIRROS CAMPO BELO I E II
}

\author{
COSTA, Wallace \\ IFTO, campus Gurupi, e-mail: wyslasw@gmail.com \\ SOARES, MONi \\ IFTO, campus Gurupi, e-mail: monikellyssoares@gmail.com \\ SILVA, Áurea \\ IFTO, campus Gurupi, e-mail: aurea.silva@ifto.edu.br
}

\begin{abstract}
RESUMO
O presente artigo tem como objetivo avaliar, de maneira qualitativa, a fase pós-ocupacional dos empreendimentos Campo Belo I e Campo Belo II, realizados pelo Programa Minha Casa Minha Vida, o PMCMV, na cidade de Gurupi, Tocantins. O mesmo foi elaborado a partir pesquisas documentais, levantamento de dados dos empreendimentos, levantamento de dados das edificações, revisões bibliográficas e estudos de campo. Os resultados obtidos demonstraram, nas edificações, em sua maioria, a necessidade de modificações realizadas pelos usuários, estas, sem atenção às normas existentes, além de más implantações das construções no loteamento. Ainda foram apresentadas sugestões de ampliação fornecidas pelo Manual do Proprietário, que demonstra as dimensões mínimas, ambientes de perspectiva de iluminação e a garantia das edificações, notando-se a falta de sistemas que garantam resfriamento e ventilação, em análise a região a qual as habitações se encontram. No empreendimento, notou-se a escassez de comércios e serviços públicos básicos, a ausência de drenagem urbana, além da distância dos setores até o centro da cidade, ocorrendo-se a marginalização do mesmo. As conclusões se remeteram ao fato de o PMCMV não atender eficientemente a seus beneficiários por não levar em consideração fatores sociais, econômicos e ambientais, que implicam diretamente na realização do programa de necessidades de seus clientes. Ainda se destacou a importância de pesquisas que examinem o desempenho de habitações sociais, visando a melhoria que tais estudos possam acarretar nas mesmas.
\end{abstract}

Palavras-chave: Habitação de interesse social, Arquitetura, Programa Minha Casa Minha Vida.

\begin{abstract}
This article aims to qualitatively evaluate a post-occupation phase of the Campo Belo I and Campo Belo II projects, carried out by the Minha Casa Program, the PMCMV, in the city of Gurupi, Tocantins. The same was produced from documents, survey of data of enterprises, data collection of the evaluations, bibliographical reviews and field studies. The results obtained demonstrate, in the majority of buildings, the performance standards of the users, these, without the same existent ones, besides the implantations of the constructions in the allotment. In addition, the amplification tests were developed by the Owner's Manual, which demonstrate the lack of flexibility, the environments of perspective of lighting and guarantee of the buildings, noting the lack of systems of guarantee of cooling and ventilation, in analysis of a region as dwellings meet. In the enterprise, the scarcity of basic public services and services, an absence of urban drainage, as well as the distance of the sectors to the center of the city, were observed, and the marginalization of the same was observed. Evidence was given that the PMCMV were not efficiently implemented to carry out customer needs programs. It was also highlighted the importance of researches that examine the performance of their social functions, aiming at the improvement of such studies with the use of them.
\end{abstract}

Keywords: Social Interest Housing, Architecture, My House My Life Program.

COSTA, W.; SOARES, M.; SILVA, A. Análise do Programa Minha Casa Minha Vida nos bairros Campo Belo I e II. In: SIMPÓSIO BRASILEIRO DE QUALIDADE DO PROJETO NO AMBIENTE CONSTRUÍDO, 6., 2019, Uberlândia. Anais... Uberlândia: PPGAU/FAUeD/UFU, 2019. p. 955-965. DOI https://doi.org/10.14393/sbqp 19088. 


\section{INTRODUÇÃO}

O Programa Minha Casa Minha Vida (PMCMV) é um programa habitacional com iniciativa do Governo Federal que visa minimizar o déficit habitacional no Brasil. A partir da parceria com o estado ou o município, o Governo Federal ofereceu recursos de construção de moradias para famílias que se encaixam nos requisitos de cada modalidade (CAIXA, s.d.).

Entre 2009 e 2016 ocorreu a primeira e a segunda fase do PMCMV, na qual o Governo Federal firmou o contrato para a entrega de 4.219.366 unidades habitacionais no país, sendo entregue 2.632 .953 habitações, englobando-se todos os tipos de modalidades (GOVERNO FEDERAL, 2016).

Nesse mesmo período, no estado do Tocantins, o programa previu a entrega de 30.167 unidades habitacionais, das quais foram entregues 10.121 habitações (GOVERNO FEDERAL, 2016).

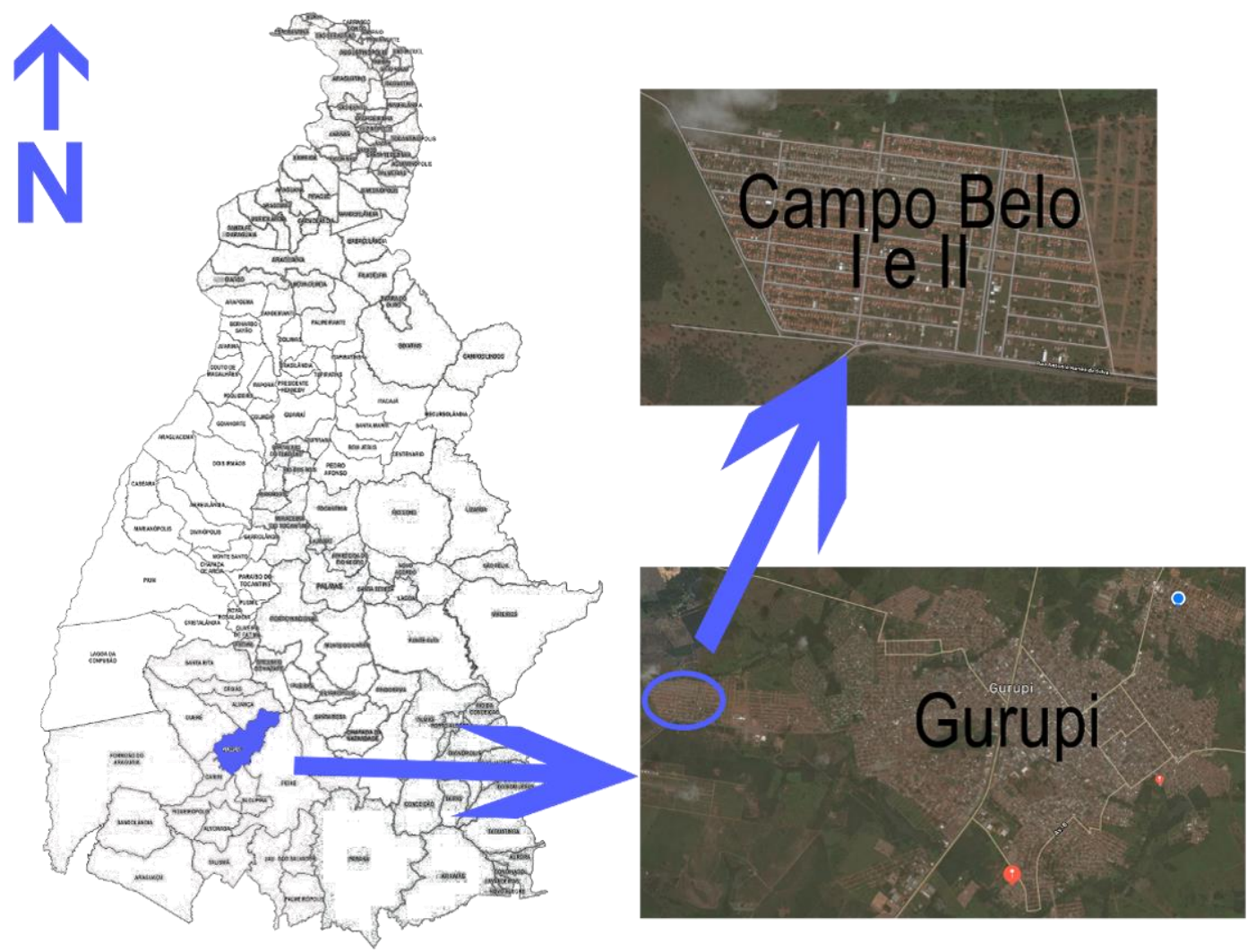

Figura 1 - Localização -

Fonte: Apple Maps, modificado pelos autores (2019)

O município de Gurupi, que está localizado na região sul do estado do Tocantins (Figura 1 - Localização), dista a $223 \mathrm{~km}$ de Palmas, capital do Estado, e possui uma população estimada de 85.737 habitantes. É terceira maior cidade do Tocantins e, segundo O IBGE (2018), impulsionou-se economicamente após a chegada da rodovia Belém-Brasília (BR-153), fator que contribuiu para o aumento populacional e a criação de grandes comércios.

De acordo com o Perfil Socioeconômico dos Municípios (2017), em 2010, a cidade contava com cerca de 23.242 domicílios particulares permanentes. A cidade foi uma das atendidas pelo PMCMV, que entre 2013 e 2015, entregou 
2.549 unidades habitacionais, divididas em 7 empreendimentos, sendo eles, João Lisboa da Cruz, Campo Belo I, Campo Belo II, Madrid, Alvorada I, Alvorada II e Morada Verde (IBGE, 2018).

Embora a maior parte dos estudos estejam focados em metrópoles e grandes cidades, seus impactos se estendem também a outros municípios e regiões, como é o caso de Gurupi, que carece de pesquisas acadêmicas voltadas ao PMCMV com demandas sociais distintas, além de clima e disposição de sistemas construtivos diferenciados.

O presente estudo busca examinar e avaliar as práticas empregadas pelo PMCMV em Gurupi e as fases pós-ocupacionais dos empreendimentos Campo Belo I e II, que contam com 477 unidades habitacionais.

\section{REVISÃO BIBLIOGRÁFICA}

As políticas brasileiras passaram por longos processos de reconfiguração, alternando-se por momentos de redução ou ampliação da atuação do Estado, sendo influenciada por conjunturas sociais e econômicas, tanto nacionais quanto internacionais (OLIVES, 2017).

Para a diminuição das desigualdades existentes, as políticas desenvolvidas tiveram como intuito o acesso a serviços e oportunidades. Dentre elas, surgiram os Programas direcionados a políticas habitacionais, que segundo Almeida (2011), se caracterizam como um direito social previsto em determinadas Constituições Nacionais (como por exemplo, na constituição brasileira e portuguesa) quanto internacionalmente, pela Organização das Nações Unidas (ONU).

Em resposta a crise de 2008, na tentativa de aquecer a política interna e diminuir o déficit habitacional, dentro do setor imobiliário brasileiro, foi aberto o capital financeiro, em tentativas a promessas de alta remuneração no setor e acesso aos fundos públicos do país. Essa relação entre ajustes econômicos, readequação de produção do capital e da força de trabalho internamente, além da promoção de política habitacional, se caracterizou como fatores impulsionantes (MARTINS, 2016).

Portanto, em 2009, com objetivo de reduzir o déficit habitacional, foi lançado o PMCMV pelo Governo Federal, oferecendo financiamento para construção e compra de imóveis (ROLNIK et al., 2015).

O programa visou atender três tipos de famílias, sendo separadas pelas seguintes modalidades: que recebem entre zero e três salários mínimos, entre quatro e seis salários mínimos e entre seis e dez salários mínimos (GOVERNO FEDERAL, 2014).

Com foco nacional, Tocantins foi um dos estados que recebeu os benefícios do programa. De acordo com Santos (2009), o estado surgiu a partir de um déficit histórico da região e sofreu com um vazio demográfico em sua criação, devido a suas políticas de desenvolvimento e concepção da região.

Os programas sociais de habitação trazem benefício e oferecem um custo, que atendem a população de baixa renda. São realizados ou em parceria ou com a participação dos usuários e dificilmente ganham espaço nos meios de comunicação. Desaparecem aos olhos dos assim chamados formadores de 
opinião, sem a divulgação de seus resultados, embora de importância para a população que foi atendida (BONDUKI, 1998).

No que tange habitação social, Bonduki (1998) descreve que é aquela em que há intervenção do governo, que controla sua distribuição e que a financia, normalmente oferecido a famílias de baixa renda.

As habitações sempre foram consideradas como um bem de consumo inatingivel por grande parte da população brasileira. Para parte das pessoas que obteve acesso, muitas vezes às fazem de forma precária (CARDOSO; RIBEIRO, 2002).

A precariedade das edificações pode surgir de sua implantação, onde não há um estudo prévio da região na qual o empreendimento foi implantado. Segundo Martucci e Basso (2002), não é possível estabelecer um padrão único de projeto habitacional que possa ser aplicado em todo o país, devido a diversidade climática, geopolítica e cultural. Por isso, é necessário um estudo prévio da região, onde possa se analisar as características únicas e definir um plano de aplicação regional.

Durante todo o tempo de atuação do PMCMV, é notório que o mesmo apresenta uma distribuição territorial injusta na implantação de seus empreendimentos, dos quais são segregados da cidade, socialmente excluídos, carecem de infraestrutura pública e são inseguros (MOURA, 2017).

\section{METODOLOGIA}

A presente pesquisa possui caráter qualitativo, na qual se busca avaliar as edificações e os empreendimentos Campo Belo I e Campo Belo II, no município de Gurupi - TO. Para o seu desenvolvimento, foram realizados os seguintes procedimentos metodológicos:

Pesquisa documental - realizada através de leitura de projetos e de informações repassados pela Prefeitura Municipal de Gurupi;

Levantamento de dados dos empreendimentos - a partir da visita in loco aos empreendimentos Campo Belo I e Campo Belo II, foi avaliado a fase pósimplantação do loteamento, a presença de equipamentos públicos, o padrão fundiário e a disposição das edificações no terreno;

Levantamento de dados da edificação - foram visitadas 5 edificações, do qual foi analisado o tipo de edificação presente e as modificações realizadas e desejadas pelas famílias.

\section{RESULTADO E DISCUSSÕES}

\subsection{Análise do Empreendimento}

As edificações entregues pelo PMCMV nos empreendimentos Campo Belo I e II possuem uma metragem total de 40,80 m2, com layout rígido (Figura 2 Planta baixa).

As edificações dos empreendimentos Campo Belo I e II foram projetadas para atender famílias de até quatro pessoas, porém, em algumas residências, verificou-se um número superior de moradores, no qual foi observado a presença de até seis habitantes. 
Nos casos estudados, os moradores modificaram os layouts das residências para atender ao seu programa de necessidades, sendo as principais modificações observadas: construção de um ambiente comercial na frente da residência, construção de muros, construção de garagem e de edícula.

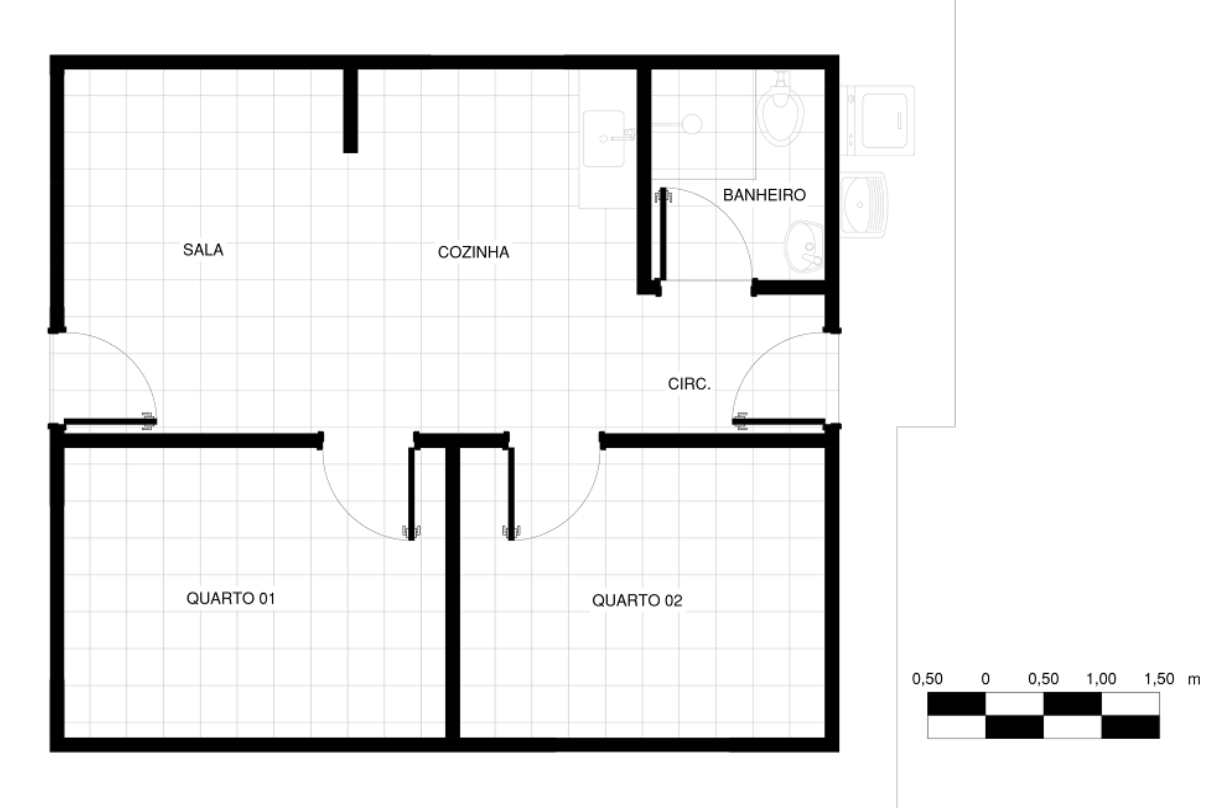

Figura 2 - Planta baixa padrão do PMCMV nos empreendimentos analisados Fonte: Autores (2019)

O Manual do Proprietário propõe ampliar a residência para o fundo da edificação (Figura 3 - Ampliação proposta), sendo que em nenhuma residência foi encontrado a ampliação sugerida. Como solução, os moradores construíram edículas, com área dos ambientes maior e que atende as necessidades da família.

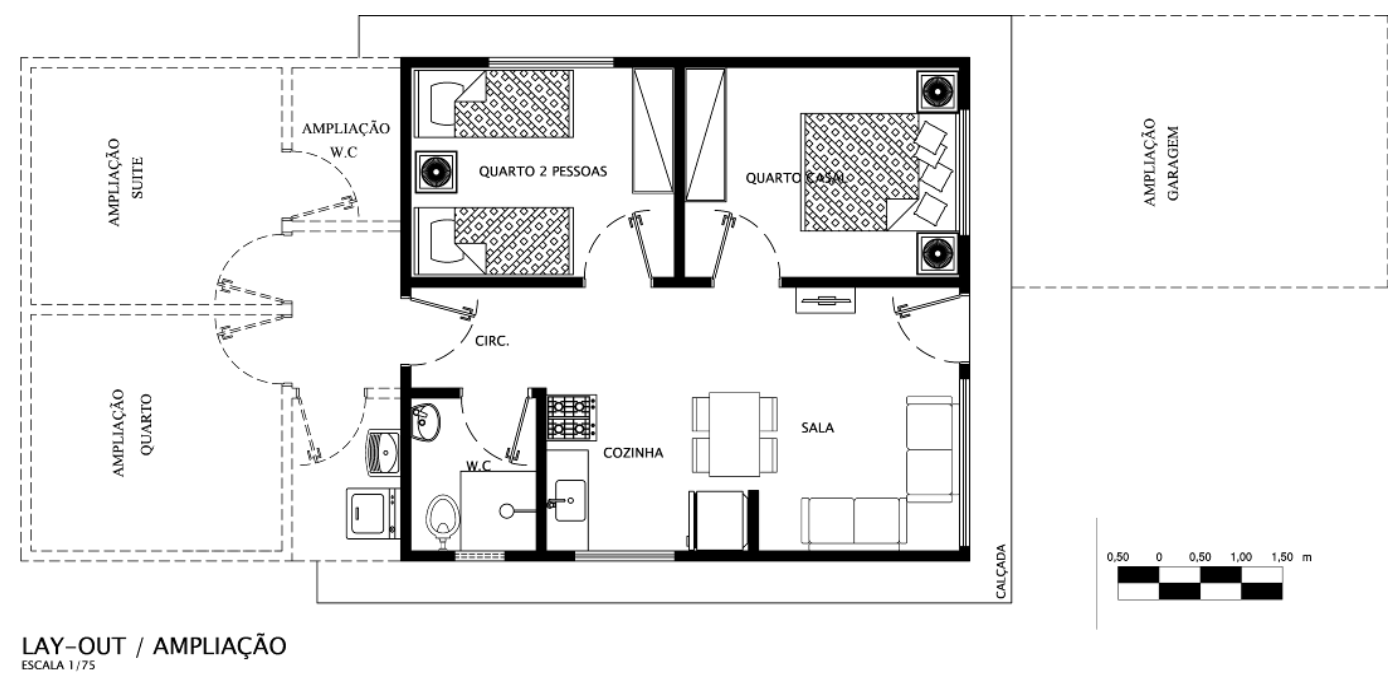

Figura 3 - Proposta de ampliação sugerida no manual do proprietário Fonte: Autores (2019)

Observou-se que as modificações realizadas pelos moradores, em muitas vezes, não atendiam à legislação municipal e a norma de desempenho, acarretando em edificações fora de norma e em ambientes desconfortáveis. 
O Código de Edificações (CE) da cidade de Gurupi estabelece as áreas e dimensões mínimas para cada compartimento (Quadro 1). Comparando o layout original do empreendimento com o CE da cidade, apenas a cozinha e o banheiro atendem a área e a dimensão mínima estabelecidas.

Quadro 1 - Áreas e dimensões mínimas dos ambientes

\begin{tabular}{|c|c|c|c|c|}
\hline Ambiente & $\begin{array}{c}\text { Área existente } \\
\left(\mathbf{m}^{\mathbf{2}} \mathbf{)}\right.\end{array}$ & $\begin{array}{c}\text { Área mínima CE } \\
\mathbf{( \% )}\end{array}$ & $\begin{array}{c}\text { Dimensão mínima } \\
\text { existente } \mathbf{( m )}\end{array}$ & $\begin{array}{c}\text { Dimensão mínima } \\
\text { CE (m) }\end{array}$ \\
\hline Sala & 7,84 & 12,00 & 2,41 & 3,00 \\
\hline Cozinha & 7,58 & 5,00 & 2,41 & 1,80 \\
\hline Banheiro & 2,73 & 2,50 & 1,50 & 1,35 \\
\hline Quarto 01 & 8,23 & 12,00 & 2,50 & 2,80 \\
\hline Quarto 02 & 7,88 & 12,00 & 2,50 & 2,80 \\
\hline
\end{tabular}

Fonte: Autores (2019)

Para cômodos de longa permanência, as aberturas devem atender aos códigos de obras, códigos sanitários e outros. É possível saber se os ambientes cumprem as normas de ventilação e iluminação (Quadro 2) ao usar a equação 1. Sendo que, em locais de permanência diurna, a abertura deve ser maior que $12,5 \%$ da área do piso, e nos noturnos, a abertura deve ser maior que $17 \%$ da área do piso.

$$
A=100 \cdot \frac{A_{a}}{A_{p}}
$$

onde, $\mathrm{A} \quad=$ Abertura destinada a ventilação e a iluminação;

$\mathrm{Aa}=$ área da abertura;

Ap = área do piso.

Os ambientes projetados inicialmente atendem às exigências de ventilação e iluminação que garantem conforto ao usuário, com menos chances de a edificação adquirir patologias oriundas da ausência de ventilação.

Quadro 2 - Áreas dos ambientes com a respectiva abertura para iluminação

\begin{tabular}{|c|c|c|}
\hline Ambiente & $\mathbf{A p}\left(\mathbf{m}^{\mathbf{2}}\right)$ & $\mathbf{A}(\boldsymbol{\%})$ \\
\hline Sala & 7,84 & 47 \\
\hline Cozinha & 7,58 & 15 \\
\hline Banheiro & 2,73 & 13 \\
\hline Quarto 01 & 8,23 & 18 \\
\hline Quarto 02 & 7,88 & 19 \\
\hline
\end{tabular}

Fonte: Autores (2019)

Após a entrega da edificação, a família recebe um Manual do Proprietário, que consta a garantia dada pela construtora de cada sistema que forma a edificação. Cada sistema da construção possui uma Vida Útil de Projeto (VUP) mínima, visto que a garantia informada no manual é bem inferior à VUP estipulada pela norma de desempenho (Quadro 3). 
Quadro 3 - Comparação da garantia fornecida pela construtora com a VUP da norma

\begin{tabular}{|c|c|c|}
\hline Sistema & $\begin{array}{c}\text { VUP mínima de acordo com a } \\
\text { norma (anos) }\end{array}$ & $\begin{array}{c}\text { Garantia fornecida pela } \\
\text { construtora }\end{array}$ \\
\hline Estrutura & $\geq 50$ & 5 \\
\hline Piso interno & $\geq 13$ & 1 \\
\hline Vedação vertical externa & $\geq 40$ & 1 \\
\hline Vedação vertical interna & $\geq 20$ & 1 \\
\hline Cobertura & $\geq 20$ & 1 \\
\hline Hidrossanitário & $\geq 20$ & 1 \\
\hline
\end{tabular}

Fonte: Autores (2019)

Um dos sistemas que compõem cada edificação dos empreendimentos é o de aquecimento de água, constituído por um boiler e uma placa solar, que faz parte da política padrão do PMCMV. Um sistema de refrigeração ou o uso de ventilação cruzada poderia ser utilizado nesse empreendimento, que está localizado em uma região que sofre com fortes ondas de calor durante o ano, com temperaturas que variam entre $23^{a} \mathrm{C}$ e $36^{a} \mathrm{C}$ de agosto a outubro, e variação entre $19^{a} \mathrm{C}$ e $33^{a} \mathrm{C}$ de novembro a abril (WEATHER SPARK, 2018), resfriamento.

\subsection{Análise do empreendimento}

Os bairros estão situados na região oeste da cidade de Gurupi (Figura 4 Localização dos bairros em relação a cidade), a uma distância de $8,5 \mathrm{~km}$ do centro da cidade e com um percurso de 30 minutos de ônibus, com intervalo de 1 hora.

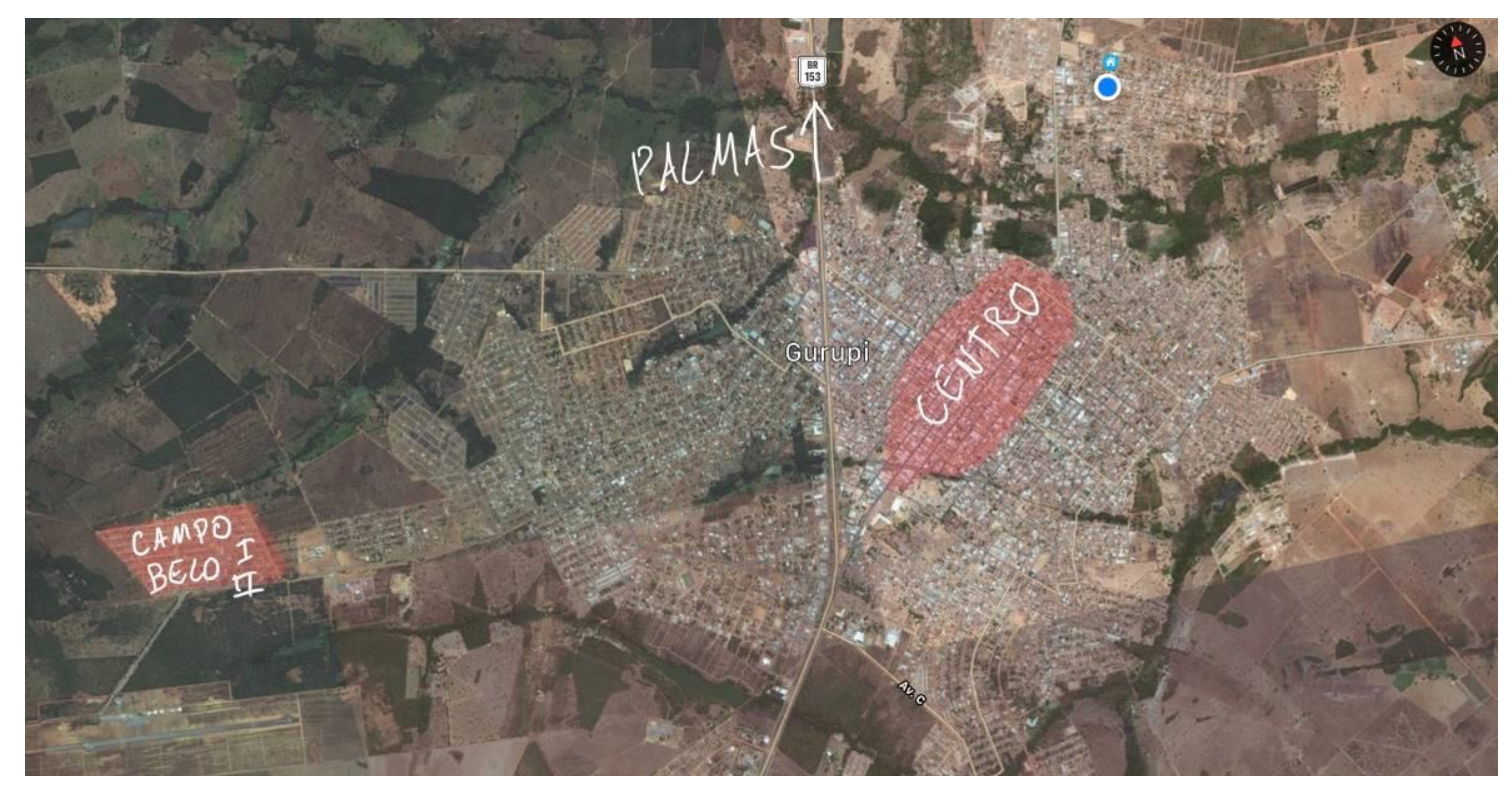

Figura 4 - Localização dos bairros em relação a área central de Gurupi Fonte: Apple Maps, modificado pelos autores (2019)

Os bairros fazem divisa entre si (Figura 5 - Divisa entre os bairros) e, somados, possuem uma área aproximada de 846 mil metros quadrados. O acesso principal se dá pela rua Antônio Nunes da Silva, via local principal, que liga vários bairros da região - única rota de acesso aos mesmos. 


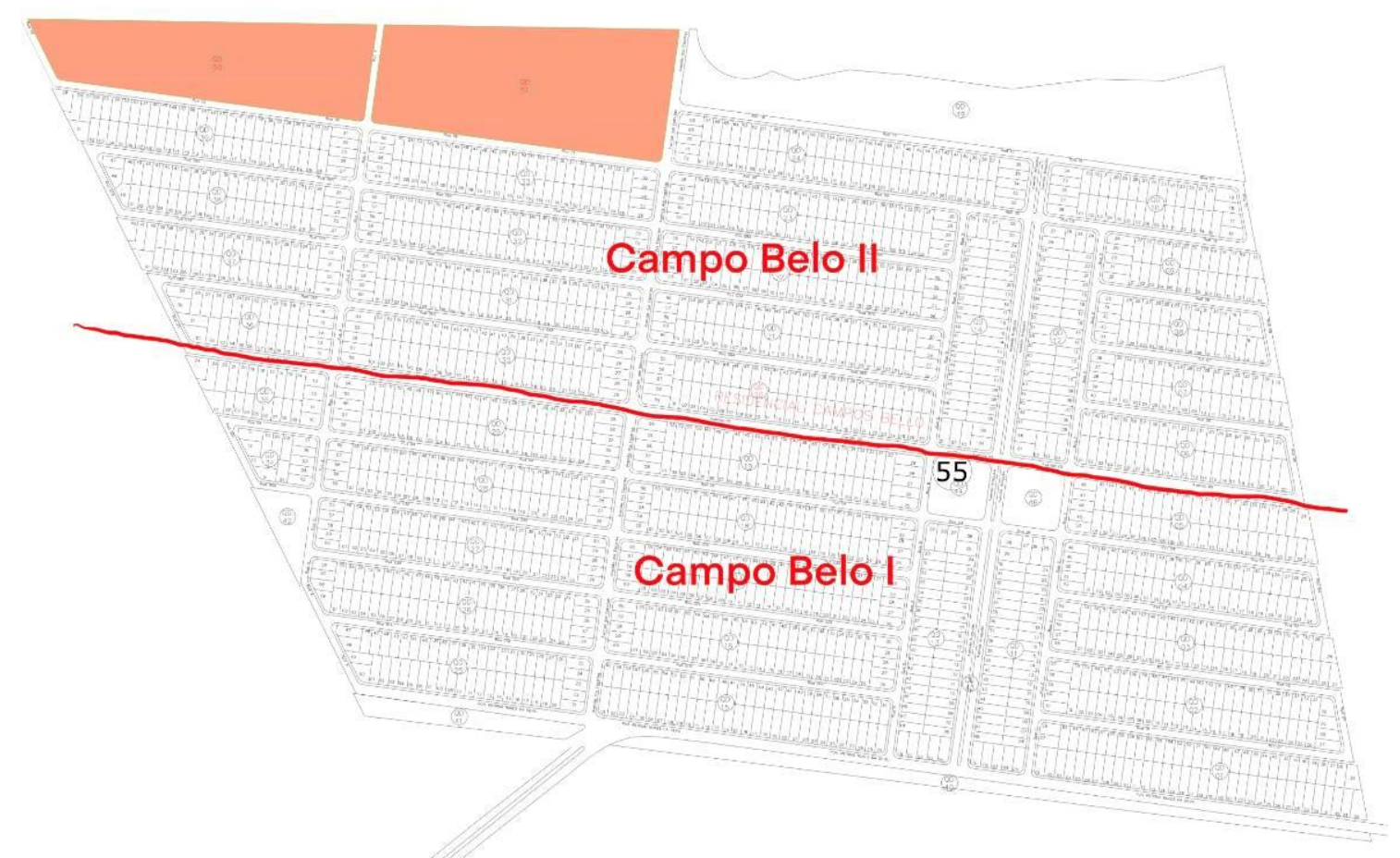

Figura 5 - Divisa entre os bairros Campo Belo I e Campo Belo II Fonte: Autores (2019)

As quadras que compõem os empreendimentos possuem formato retangular de tamanho médio, com pouca variação entre si. Os lotes, em grande maioria, são de tamanho regulares de $25 \mathrm{~m} \times 10 \mathrm{~m}$, totalizando uma área de $250 \mathrm{~m}^{2}$.

Como é um bairro predominantemente habitacional, a maioria das construções são residências, havendo a presença de pouco comércio na região, como as principais, mercearias, bares e igrejas, todos de pequeno porte. O acesso aos demais serviços e comércios só é possível ao se transitar a outros bairros ou a área central da cidade, que se distam a 5 minutos e 20 minutos de carro, respectivamente.

Os bairros carecem de equipamentos públicos e sua localização periférica dificulta o acesso a serviços essenciais aos moradores. Identificou-se, nos empreendimentos, apenas uma praça central, encontrada na divisa entre os bairros e uma creche, que está localizada na borda do bairro (Figura 6 Localização dos equipamentos públicos).

Sobre os sistemas públicos presentes nos bairros, há distribuição de energia, rede de esgoto, coleta de lixo e calçamento para circulação de pedestres. Na pesquisa de campo, ficou notório a ausência de um sistema de drenagem urbana e nos lotes.

A água provinda da chuva deveria percorrer as vias e ser despejada em um sistema urbano de saneamento. Já dentro do terreno, a água deveria ser direcionada para um sistema de drenagem, mas no empreendimento, foi observado que a água entra nas edificações, devido estar a um nível inferior do nível da via pública (Figura 7 - Perfil dos terrenos), fator que contribui com o surgimento de patologias por umidade excessiva, que além de doenças aos residentes, causam gastos excessivos para a manutenção das edificações. 


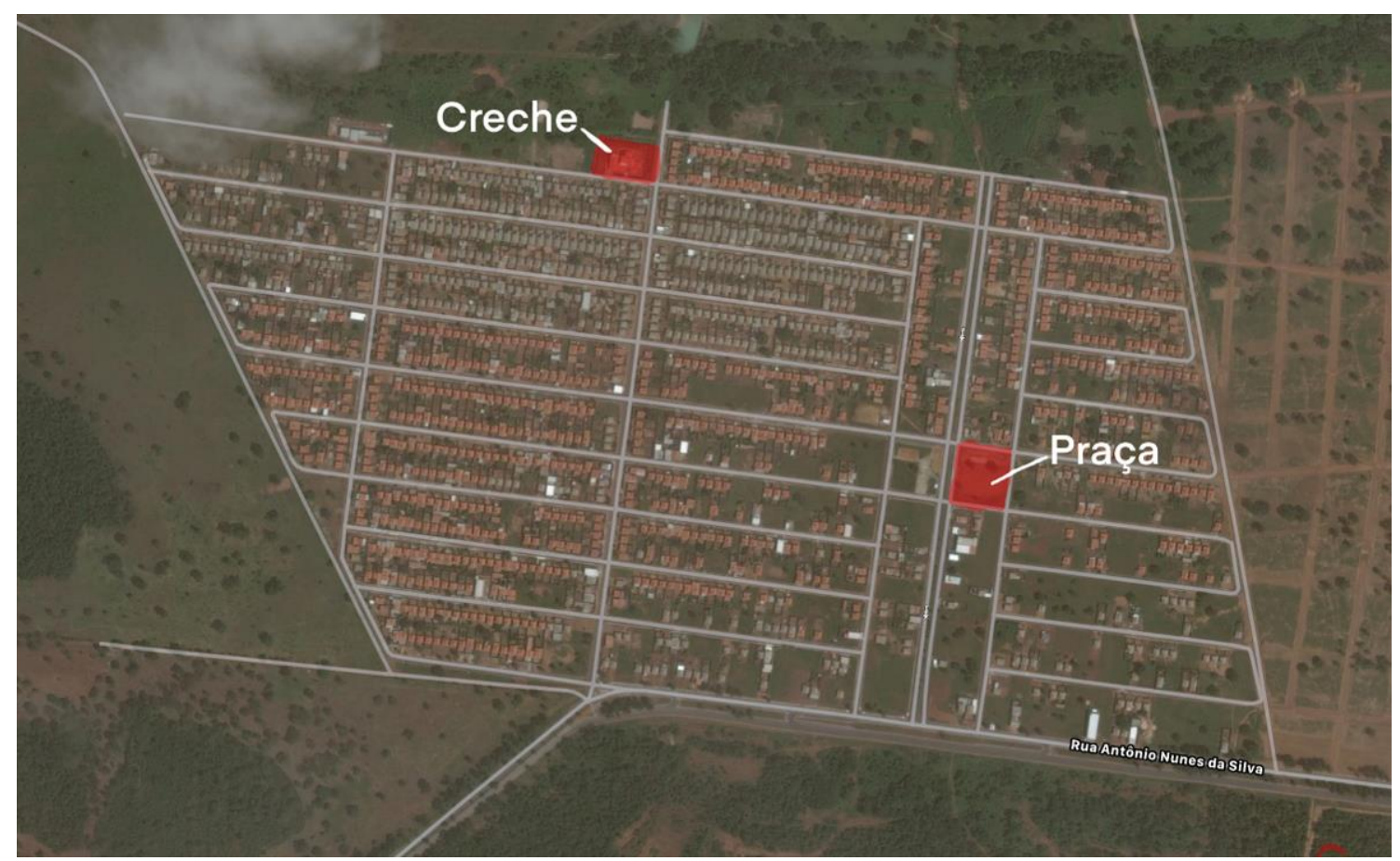

Figura 6 - Localização dos equipamentos públicos nos bairros Fonte: Apple Maps, modificado pelos autores (2019)

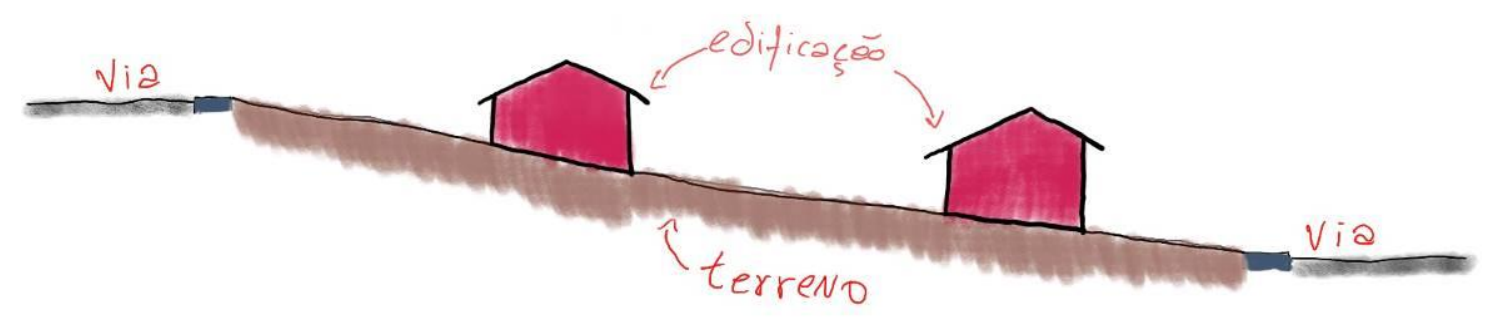

Figura 7 - Perfil dos terrenos em relação à via pública -

Fonte: Autores (2019)

O layout das construções é o mesmo em todo o empreendimento, fator crítico na implantação das mesmas nos bairros, que contribui para o desconforto do usuário, já que a posição dos ambientes em relação ao sol é um fator importante a ser analisado.

\section{CONSIDERAÇŌES FINAIS}

Durante a última década, observou-se o crescimento do PMCMV na entrega de habitações populares, reafirmando as periferias urbanas. Com o foco em números, o PMCMV teve como objetivo entregar 4.219 .366 unidades habitacionais até 2016, conseguindo entregar $62,4 \%$ nesse período. Fatores sociais e regionais foram deixados em segundo plano na implantação de tais empreendimentos, visto que o projeto se trata de uma medida emergencial.

O planejamento inicial e o detalhamento dos projetos são fatores decisivos que garantem a vida útil do empreendimento, adaptando os mesmos de forma eficiente a área implantada.

Além de ser um programa de política habitacional, o PMCMV deveria ser exemplo de inovação e sustentabilidade, adotando sistemas sustentáveis e 
eficientes em seus empreendimentos, como o uso de painéis solares na geração de energia ou o direcionamento de águas cinzas para os sistemas sanitários, que reduzam o consumo da edificação e os gastos dos usuários.

O estudo de desempenho das edificações projetadas pelo PMCMV implica na observação de diversos aspectos, como econômicos, sociais e ambientais. Um programa de necessidades só se torna eficiente quando feita a análise de tais fatores, que se caracterizam pela identificação dos tipos de indivíduos farão uso desta edificação - renda, composição de núcleo familiar - e a localização na qual se encontra, para fim de observações climatológicas. Os levantamentos são responsáveis pela escolha de métodos construtivos sistemas que se encaixem a dada habitação.

As práticas adotadas pelo PMCMV nos empreendimentos analisados, reforçam o estudo sobre os demais empreendimentos, os caracterizando e intensificando a produção acadêmica regional, carente de pesquisas sociais relacionadas ao programa e a habitações.

\section{REFERÊNCIAS}

ALMEIDA, I. F. G. Desigualdades e políticas públicas de habitação no Brasil. 201 1. Dissertação (Mestrado) - Faculdade de Ciências Econômicas, Universidade Federal da Bahia, Salvador, 2011.

ASSOCIAÇÃO BRASILEIRA DE NORMAS TÉCNICAS. NBR 15575-1: Requisitos gerais. Rio de janeiro. 2013.

NBR 15575-4: Sistemas de vedações verticais internas e externas -

SVVIE. Rio de janeiro. 2013.

BONDUKI, N. Origens da Habitação Social no Brasil. São Paulo: Estação Liberdade, 1998.

CAIXA. Minha casa minha vida - habitação urbana. Disponível em: <http://www.caixa.gov.br/voce/habitacao/minha-casa-minhavida/urbana/paginas/default.aspx>. Acesso em: 06 jun. 2019.

CARDOSO, A.; RIBEIRO, L. Os municípios e as políticas habitacionais. Inserção urbana e avaliação pós-ocupação (APO) da habitação de interesse social. São Paulo, FAUUSP, 2002.

GOVERNO DO ESTADO DO TOCANTINS. Perfil socioeconômico dos municípios: Gurupi. Palmas, 2017.

Dados estatísticos do Programa Minha Casa, Minha Vida - Pedido

80200000217201678. Disponível em:

<http://www.consultaesic.cgu.gov.br/busca/dados/Lists/Pedido/ltem/displayifs .aspx? List=0c839f31-47d7-4485-ab65-

ab0cee9cf8fe \&ID $=460428 \& W e b=88 c c 5 f 44-8 c f e-4964-8 f f 4-376 b 5 e b b 3 b e f>$.

Acesso em: 02 jun. 2016.

GOVERNO FEDERAL. Programa de Aceleração do Crescimento - Minha Casa,

Minha Vida. Disponível em: <http://www.pac.gov.br/minha-casa-minha-vida>. Acesso em 06 jun. 2019.

IBGE. Gurupi. Disponível em: <https://cidades.ibge.gov.br/brasil/to/gurupi>.

Acesso em: 06 jun. 2019. 
Estimativas da População. Disponível em:

<https://www.ibge.gov.br/estatisticas/sociais/populacao/9103-estimativas-depopulacao.htmle=\&t=downloads $>$ Acesso em: 08 de junho de 2019.

MARTINS, B. X. O programa Minha Casa Minha Vida: a mercadoria habitação a serviço da reprodução do capital em contexto de crise. 2016. Dissertação (Mestrado) - Faculdade de Filosofia, Letras e Ciências Humanas, Universidade de São Paulo, São Paulo, 2016.

MARTUCCI, R.; BASSO, A. Uma visão integrada da análise e avaliação de conjuntos habitacionais: aspectos metodológicos da pós-ocupação e do desempenho tecnológico. Coletânea Habitare, v. 1, p. 26, 2002.

MOURA, J. M. Programa Minha Casa, Minha Vida na Região Metropolitana de Natal: uma análise espacial dos padrões de segregação e desterritorialização. Revista Brasileira de Gestão Urbana, v. 6, n. 3, p. 339-359, 2017.

OLIVES, S. J. C. Desafios e fragilidades do trabalho social no Programa Minha Casa Minha Vida na região metropolitana de Natal. 2017. Dissertação (Mestrado) - Universidade Federal do Rio Grande do Norte, Natal, 2017.

ROLNIK, R. et al. O Programa Minha Casa Minha Vida nas regiões metropolitanas de São Paulo e Campinas: aspectos socioespaciais e segregação. Cadernos Metrópole, v. 17, n. 33, p. 127-154, 2015.

RUBIN, G. R.; BOLFE, S. A. O desenvolvimento da habitação social no Brasil. Ciência e Natura, v. 36, n. 2, 2014.

SANTOS, R. S. Estado nacional e desenvolvimento econômico na Amazônia Oriental: modelos de ação estatal e representações da modernização induzida nos últimos 40 anos. Amazônia: desenvolvimento e meio ambiente e diversidade sociocultural. São Luis: Edufma, 2009.

WEATHER SPARK. Condições meteorológicas médias de gurupi. Disponível em: <https://pt.weatherspark.com/y/29996/clima-caracter\%c3\%adstico-em-gurupibrasil-durante-o-ano>. Acesso em: 07 jun. 2019. 